\title{
US proposes new rules for dealing with misconduct
}

\section{Washington}

THE US Department of Health and Human Services (HHS) has proposed new rules for dealing with and reporting possible misconduct involving research paid for by the Public Health Service (PHS). The department will also publish a preliminary announcement that it will seek comments on several strategies designed to prevent scientific misconduct.

In July 1986, the National Institutes of Health produced guidelines for dealing with scientific misconduct as part of a set of rules governing all contracts and grants. But these do not have the same legal weight as departmental rules. Earlier this year, PHS sought to publish its own rules, only to find its plans thwarted by the White House Office of Management and Budget (OMB). OMB is said to have felt that PHS's first attempt was too restrictive, and asked for a new strategy.

PHS responded with two documents. One, which will take effect after a 60day comment period, deals with the particular responsibilities of institutions in coping with charges of misconduct. The new rule defines misconduct in science as "serious deviation" from accepted practices for conducting research, such as plagiarism, or falsification or fabrication of data. Failing to comply with federal requirements for conducting research would also qualify as misconduct.

The new rules would require grantee institutions to notify the appropriate funding agency in writing of any misconduct investigations. The timetable for completing investigations would be 60 days for an initial inquiry, and 120 days for a complete investigation, with extensions only when requested in writing. These time periods may change depending on the comments received publication of the rules.

The second document is an attempt to develop before-the-fact prevention strategies. PHS makes it clear that the term 'scientific misconduct' has been chosen over scientific fraud because of the common legal definition of fraud. Robert Charrow, HHS deputy council, speaking last week to a workshop on scientific misconduct sponsored by the Institute of Medicine, explained that for the government to prove it has been the victim of fraud, it would have to show that an researcher had misrepresented his work at the time he applied for a federal grant. Charrow argues that an researcher could represent his data accurately even though he knew it was in error, making it impossible for the government to prove it was defrauded.

PHS is also trying to determine which agency should investigate allegations of misconduct. Institutions which investigate questionable practices by their own faculty members face difficulties that may be insurmountable. PHS is considering placing all such investigations in the hands of the HHS Inspector General's office. To encourage compliance with proper research practices, PHS is also looking into imposing sanctions against institutions convicted of inappropriate actions.

PHS is not alone in pursuing these issues. In Congress, the House of Representatives government operations subcommittee on human resources, chaired by Ted Weiss (Democrat, New York), has been considering possible legislative changes to encourage compliance with proper scientific practices. Following the Institute of Medicine workshop last week, the National Academy of Sciences Committee on Science, Education and Public Policy will transmit recommendations for preventing misconduct to the National Institutes of Health later this year. The American Association of Universities is also coordinating an effort involving 10 other groups to develop a comprehensive framework for dealing with misconduct. This framework will be discussed at a workshop sponsored by the American Association for the Advancement of Science and the American Bar Association later this month.

\section{International dispute at the BA}

\section{Oxford}

INTERNATIONAL collaboration in science is a good thing, agreed a group of eminent researchers from around the world in a debate at the annual meeting of the British Association for the Advancement of Science held in Oxford last week.

But the practical difficulties revealed in the course of the debate led even its chairman, Professor Sam Edwards of the University of Cambridge, to admit that his own policy on internationalism is "to encourage it and hope that it doesn't happen”.

The discussion group included Dr Walter Massey, president of the BA's sister organization in the United States, Academician Rem Petrov, president of the Soviet Union's Society of Immunologists, and others from India, China, Africa and Europe. At first everyone heartily agreed that international cooperation is good for science, although the reasons given varied widely. Massey argued the wasteful expense of competition in big science projects. Petrov argued that collaboration gives valuable insight into other modes of thinking. But everyone seemed to agree that mechanisms to facilitate collaboration are necessary, and the speakers were applauded politely.

But the arrival of a rowdy bunch from the Institute of Physics late in the afternoon injected controversy into the proceedings; with several delegates trying to shout each other down, it was hard at times to keep track of the arguments. Someone suggested that researchers are forced into collaboration only when work in their local environment is unsuccessful. Many argued that policies for collaboration are unnecessary; they only increase the growing amount of scientific bureaucracy and can actually destroy collaboration at grassroots level. There were warnings of the build-up of a community of "scientific tourists", flying round the world with one motto - "have paper will travel".
And some international projects, with no single clearly defined aim, easily become "talking shops", it was claimed. As the chairman drew the debate to a close, six hours after it had begun, everyone hurried

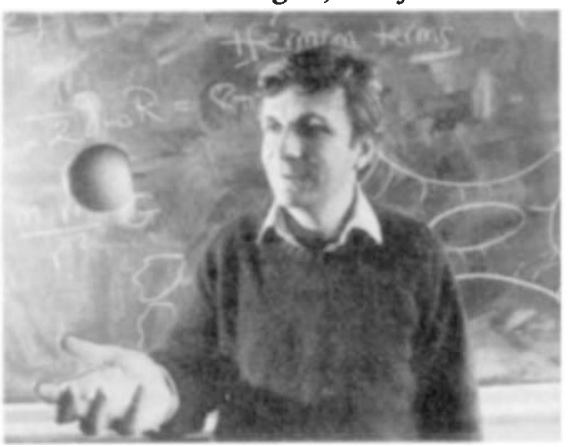

Michael Green unifying the physical forces.

off, some no doubt counting the hours of research wasted in talking that day. Others, though hurried off to fight for a seat in the crowded lecture theatre where Professor Michael Green of Queen Mary College, London, was explaining the theory of superstrings.

Debate of a different kind raged in Oxford last week, with accusations flying around as to who should be responsible for reinjecting life into British science. Sir Walter Bodmer, this year's president of the association, criticized the government for the decreasing public support for science. But Mr Kenneth Baker, the Secretary of State for Education and Science, said the government was spending more than ever on basic research, and he lamented the lack of investment in science by British industry. He also questioned the value of conferences such as this one to resolve the issue. "The question is now widely recognized and discussed, but action must result or all this activity will have been a waste of time." And that action, he said, is not the government's responsibility; it can take place only within individual institutions and companies.

Christine McGourty 